\title{
Wnt/ $\beta$-catenin interacts with the FGF pathway to promote proliferation and regenerative cell proliferation in the zebrafish lateral line neuromast
}

\author{
Dongmei Tang ${ }^{1}$, Yingzi He${ }^{1}$, Wenyan $\mathrm{Li}^{1}$ and Huawei $\mathrm{Li}^{1,2,3,4,5}$
}

\begin{abstract}
Wnt and FGF are highly conserved signaling pathways found in various organs and have been identified as important regulators of auditory organ development. In this study, we used the zebrafish lateral line system to study the cooperative roles of the Wnt and FGF pathways in regulating progenitor cell proliferation and regenerative cell proliferation. We found that activation of Wnt signaling induced cell proliferation and increased the number of hair cells in both developing and regenerating neuromasts. We further demonstrated that FGF signaling was critically involved in Wnt-regulated proliferation, and inhibition of FGF abolished the Wnt stimulation-mediated effects on cell proliferation, while activating FGF signaling with basic fibroblast growth factor (bFGF) led to a partial rescue of the proliferative failure and hair cell defects in the absence of Wnt activity. Whole-mount in situ hybridization analysis showed that the expression of several FGF pathway genes, including pea3 and fgfr 1 , was increased in neuromasts after treatment with the Wnt pathway inducer BIO. Interestingly, when SU5402 was used to inhibit FGF signaling, neuromast cells expressed much lower levels of the FGF receptor gene, fgfr 1, but produced increased levels of Wnt target genes, including ctnnb1, ctnnb2, and tcf712, while bFGF treatment produced no alterations in the expression of those genes, suggesting that fgfr 1 might restrict Wnt signaling in neuromasts during proliferation. In summary, our analysis demonstrates that both the Wnt and FGF pathways are tightly integrated to modulate the proliferation of progenitor cells during early neuromast development and regenerative cell proliferation after neomycin-induced injury in the zebrafish neuromast.
\end{abstract}

\section{Introduction}

Cell proliferation is a critical process guiding many aspects of auditory organ specification and morphogenesis during embryonic development, and its misregulation is associated with various malformations. However, the precise molecular signaling pathways that control proliferation and their coordination remain unclear.

\footnotetext{
Correspondence: Huawei Li (hwli@shmu.edu.cn)

${ }^{1}$ ENT institute and Otorhinolaryngology Department of Affiliated Eye and ENT Hospital, State Key Laboratory of Medical Neurobiology, Fudan University, Shanghai 200031, China

${ }^{2}$ Institutes of Biomedical Sciences, Fudan University, Shanghai 200032, China Full list of author information is available at the end of the article.

These authors contributed equally: Dongmei Tang, Yingzi He
}

The zebrafish lateral line is a powerful vertebrate model system for the in vivo study of sensory organ developmental biology due to its well-established genetics and ease of in vivo visualization and manipulation. The posterior lateral line (pLL) comprises a series of mechanosensory organs called neuromasts, which lie on the surface of both the head and body. Neuromasts are composed of sensory hair cells (HCs) in the center that are surrounded by nonsensory supporting cells $(\mathrm{SCs})^{1,2}$. Mechanosensory HCs share many structural, molecular, and functional similarities with vertebrate inner ear $\mathrm{HCs}$ and thus are an excellent model system for studying $\mathrm{HC}$ biology related to hearing and balance and for unraveling

\section{(c) The Author(s) 2019}

(c) (i) Open Access This article is licensed under a Creative Commons Attribution 4.0 International License, which permits use, sharing, adaptation, distribution and reproduction cc) in any medium or format, as long as you give appropriate credit to the original author(s) and the source, provide a link to the Creative Commons license, and indicate if changes were made. The images or other third party material in this article are included in the article's Creative Commons license, unless indicated otherwise in a credit line to the material. If material is not included in the article's Creative Commons license and your intended use is not permitted by statutory regulation or exceeds the permitted use, you will need to obtain permission directly from the copyright holder. To view a copy of this license, visit http://creativecommons.org/licenses/by/4.0/. 
their genetic control ${ }^{3,4}$. However, unlike mammals, zebrafish retain the ability to quickly regenerate $\mathrm{HCs}$ after damage $^{5-8}$. Thus, the molecular signaling pathways that guide $\mathrm{HC}$ regeneration in the zebrafish lateral line are of great biological and clinical interest.

Previous studies have revealed that the development of the pLL requires complex coordination among diverse molecular signaling pathways, including chemokine signaling ${ }^{9-11}$, FGF signaling ${ }^{11-13}$, and $\mathrm{Wnt} / \beta$-catenin signaling ${ }^{10,11}$. Most of our current understanding about these pathways is related to early embryonic pLL formation, which entails primordium formation, migration, and deposition stages; however, the precise molecular signaling that initiates and guides cell proliferation and $\mathrm{HC}$ regeneration in zebrafish neuromasts remains poorly defined. The Wnt/ $\beta$-catenin signaling pathway is a wellknown signaling cascade that plays central roles in embryonic development and organogenesis by modulating cell migration, proliferation, and specification ${ }^{14}$. During the early stages of zebrafish pLL development, $\mathrm{Wnt} / \beta$-catenin signaling is active in the leading part of the primordium and is necessary for cell proliferation and proneuromast formation as the primordium migrates along the body of the organism ${ }^{15-17}$. Constitutive activation of canonical Wnt signaling broadly promotes cellular proliferation throughout the primordium but stalls migration during developmental patterning, whereas pharmacological or genetic inhibition of Wnt reduces cellular proliferation, increases cell death, and results in a dramatic truncation of the $\mathrm{pLL}^{10,11,18}$. Recently, activation of the $\mathrm{Wnt} / \beta$-catenin pathway was reported to promote proliferation and increase $\mathrm{HC}$ generation in the developing and regenerating zebrafish lateral line ${ }^{19}$. Conversely, inhibition of canonical Wnt signaling decreases proliferation and arrests neuromast morphogenesis at an early stage of neuromast development. Little is known, however, about the molecular mechanisms underlying this signal transduction during the periods of proliferation and $\mathrm{HC}$ regeneration in neuromasts.

FGF signaling has been shown to regulate cell migration and cell fate changes during embryonic development ${ }^{20}$, and FGF is active in the trailing region of the zebrafish pLL primordium, which contains two or three rosetteshaped proneuromasts. FGF acts as a key molecule in promoting the epithelialization and formation of the proneuromasts in the course of the migration of the primordium $^{12,13}$, and FGF inhibition leads to a loss of apically constricted rosettes and aberrant migration of the primordium. FGF activation not only induces proneuromast formation by initiating the organization of center-oriented epithelial rosettes but also initiates the specification of $\mathrm{HC}$ precursors by regulating atoh1a expression ${ }^{12,13}$. Although the function of FGF signaling in facilitating pLL morphogenesis has been reasonably well studied, its contribution to proliferation during the establishment of the pLL and to regenerative cell proliferation has not been well addressed.

In this study, we used pharmacological agonists and antagonists and transgenic zebrafish to regulate Wnt and FGF signaling, and we found significantly more proliferating cells and more $\mathrm{HCs}$ and SCs after activation of Wnt or FGF signaling. To further understand whether the Wnt and FGF pathways act synergistically to regulate proliferation, we performed epistasis experiments to verify the mechanisms underlying proliferation in neuromasts. We stimulated Wnt signaling first and then inhibited FGF activity and found that the proliferation of the progenitors induced by Wnt activation disappeared after blocking FGF in Wnt-activated embryos. Conversely, we found that inhibition of Wnt signaling using the DKK1 conditional knockout transgenic line or IWR-1 treatment followed by treatment with basic fibroblast growth factor (bFGF) resulted in significantly more proliferating cells than in the group treated with IWR-1 alone, suggesting that activation of FGF could partly rescue proliferation failure caused by Wnt signaling inhibition. Similar results were observed in HC regeneration experiments. To better understand the interactions of both signaling pathways during cell proliferation in the larval zebrafish neuromast, we performed whole-mount in situ hybridization analysis. We showed that the $f g f 3$ and $f g f 10$ genes were Wnt targets during neuromast cell proliferation and acted to modulate FGF activity and that $f g f r 1$, an FGF target gene, acted to repress Wnt activity. Taken together, our findings suggest that the Wnt and FGF signaling pathways are tightly connected to regulate developmental cell proliferation and regenerative cell proliferation in the zebrafish pLL neuromast.

\section{Materials and methods \\ Fish strains and maintenance}

Embryos were obtained by natural spawning and developed at $28.5^{\circ} \mathrm{C}$ in E3 medium. They were staged according to standard protocols ${ }^{21}$, and embryo ages were marked as hours post fertilization (hpf). The wild-type strain was derived from the $\mathrm{AB}$ line, and the $\operatorname{Tg}(\mathrm{brn} 3 \mathrm{c}$ : $m G F P)^{s 356 t}$ line was used to visualize HCs. The $a p c^{m c r}$ line was a generous gift from Professor Xu Wang. APC genotyping primers were as follows: APCR-CAT GGC TCA CTC TGC ACA; APCWTF-ATA ATG TTG CAG CTG ACC; and APCMTF-ATA ATG TTG CAG CTG ACT. $\mathrm{Tg}$ (hsp 70l:dkk1b-GFP) offspring were incubated at $42^{\circ} \mathrm{C}$ for $5 \mathrm{~min}$ at $48 \mathrm{hpf}$ and allowed to recover at $28.5^{\circ} \mathrm{C}$ to inhibit Wnt signaling. Approximately $50 \%$ of the embryos did not turn green, and these served as controls. To prevent pigment formation, embryos were treated with 0.003\% 1-phenyl-2-thiourea (PTU, Sigma-Aldrich, St. Louis, MO, USA) in E3 water from $14 \mathrm{hpf}$ onwards. The 
larvae were anesthetized in 0.02\% MS-222 (SigmaAldrich, Inc.) before fixation. All zebrafish experiments were performed following the institutional guidelines approved by the Institutional Animal Care and Use Committee of Fudan University, Shanghai.

\section{Pharmacological treatment}

We used $1 \mu \mathrm{M}$ BIO to activate Wnt signaling and $10 \mu \mathrm{M}$ IWR-1 (Sigma-Aldrich) to inhibit Wnt signaling, and we used $5 \mu \mathrm{M}$ SU5402 (Calbiochem) to inhibit FGF signaling and $20 \mathrm{ng} / \mathrm{ml}$ bFGF (Invitrogen) to activate FGF signaling. Neomycin sulfate (Sigma-Aldrich) was added to a final concentration of $400 \mu \mathrm{M}$, and the $5 \mathrm{dpf}$ larvae were incubated for one hour, followed by three rinses in fresh egg water. The larvae were then allowed to recover at $28.5^{\circ} \mathrm{C}$

\section{BrdU incorporation and immunohistochemistry}

For immunofluorescence experiments, $10 \mathrm{mM}$ BrdU (Sigma-Aldrich) was coincubated with the pharmacological treatments described above to label the proliferating cells. Zebrafish larvae were fixed with 4\% PFA for $2 \mathrm{~h}$ at room temperature and washed three times with PBT-2 (PBS containing 1\% Triton X-100). For DNA denaturing, the fixed larvae were treated with $2 \mathrm{~N} \mathrm{HCl}$ for $30 \mathrm{~min}$ at $37^{\circ} \mathrm{C}$ followed by three rinses with PBT-2. Before antibody staining, the larvae were incubated in blocking solution (10\% donkey serum in PBT-2) for $1 \mathrm{~h}$ at $37^{\circ} \mathrm{C}$. The primary antibodies were anti-Sox2 (1:200 dilution; Abcam), anti-BrdU (1:200 dilution; Santa Cruz Biotechnology), anti-GFP (1:500 dilution; Abcam), and antiMyosin VI (1:200 dilution; Proteus BioSciences). After incubation with primary antibodies overnight at $4{ }^{\circ} \mathrm{C}$, the larvae were washed three times with PBT-2 and then incubated with Alexa Fluor 488-, 594-, and/or 647conjugated secondary antibodies (1:200 dilution; Jackson ImmunoResearch Laboratories, West Grove, PA, USA) for $1 \mathrm{~h}$ at $37^{\circ} \mathrm{C}$. After the larvae were washed several times in PBT-2, they were incubated with DAPI (1:800 dilution; Invitrogen) for $20 \mathrm{~min}$ to label the nuclei.

\section{Imaging and cell counts}

Fluorescent specimens were examined using a Leica confocal microscope (TCS SP8; Leica, Wetzlar, Germany). All images were edited using Adobe Photoshop CS6. The labeled cells in the pLL neuromasts (pLL2-pLL5) were counted in the confocal and fluorescence images using the counting and measuring tools in Adobe Photoshop CS6.

\section{Whole-mount in situ hybridization}

Digoxigenin-labeled probes were prepared as recommended by the manufacturer (Roche, Mannheim,
Germany). Primers for cloning the examined genes are listed in Table S1. Regular whole-mount in situ hybridization (WISH) of zebrafish embryos was performed as previously described ${ }^{22}$. After the color reaction, the embryos were mounted with $100 \%$ glycerol and observed under a bright field microscope (Nikon Instruments). Binding sites were identified as blue-black dots.

\section{TUNEL staining}

Apoptotic cells in the trunk of the zebrafish were detected by TUNEL assay (In Situ Cell Death Detection Kit, Roche). After the larvae were rinsed three times with PBT-2, they were incubated with the TUNEL reaction mixture in a humid dark chamber at $37^{\circ} \mathrm{C}$ for $1 \mathrm{~h}$ and then labeled with DAPI to visualize the nuclei.

\section{Statistical analysis}

All statistical analyses were performed with GraphPad Prism 6 Software (GraphPad, San Diego, CA, USA). Cell counts were analyzed using Student's $t$-tests and one-way ANOVA. In all figures, error bars represent the mean \pm SEM. $p<0.05$ was considered statistically significant, and $p<0.001$ was considered highly significant. "Shows the comparison with controls, and " is used when the Wnt and FGF signaling pathways were shown to interact.

\section{Results}

The role of $W n t / \beta$-catenin signaling in the developing neuromast of the zebrafish pLL

To determine in detail how $\mathrm{Wnt} / \beta$-catenin signaling affects early neuromast development, BIO and IWR-1 were used to modulate Wnt activity at $48 \mathrm{hpf}$ when the neuromasts along the trunk and tail had all been deposited and the neuromast cells were undergoing high levels of proliferation. The effects of the treatments were detected by WISH with known markers of Wnt signaling, including ctnnb1, ctnnb2, and tcf7l2. After $24 \mathrm{~h}$ of pharmacological treatment, a significant increase in ctnnb1, $c t n n b 2$, and $t c f 7 l 2$ expression was observed in the $1 \mu \mathrm{M}$ BIO-treated group, indicating induction of Wnt signaling, whereas $10 \mu \mathrm{M}$ IWR-1 significantly inhibited the expression of these genes (Supplementary Fig. 1). Thus, $1 \mu \mathrm{M}$ $\mathrm{BIO}$ and $10 \mu \mathrm{M}$ IWR-1 were used for all subsequent experiments in this study.

To simplify the identification of neuromast cells, we used the $\operatorname{tg}(B r n 3 c: m G F P)$ transgenic line that expresses GFP in the HC membrane ${ }^{23}$, and the SCs were marked and counted by Sox2 immunostaining. Beginning at $48 \mathrm{hpf}$, embryos were treated with BIO or IWR-1 in the presence of BrdU for a period of $24 \mathrm{~h}$. Quantification showed significantly more $\mathrm{BrdU}^{+}$cells, $\mathrm{GFP}^{+} \mathrm{HCs}$, and $\mathrm{Sox}^{+}$SCs in the BIO-treated neuromasts than in the 


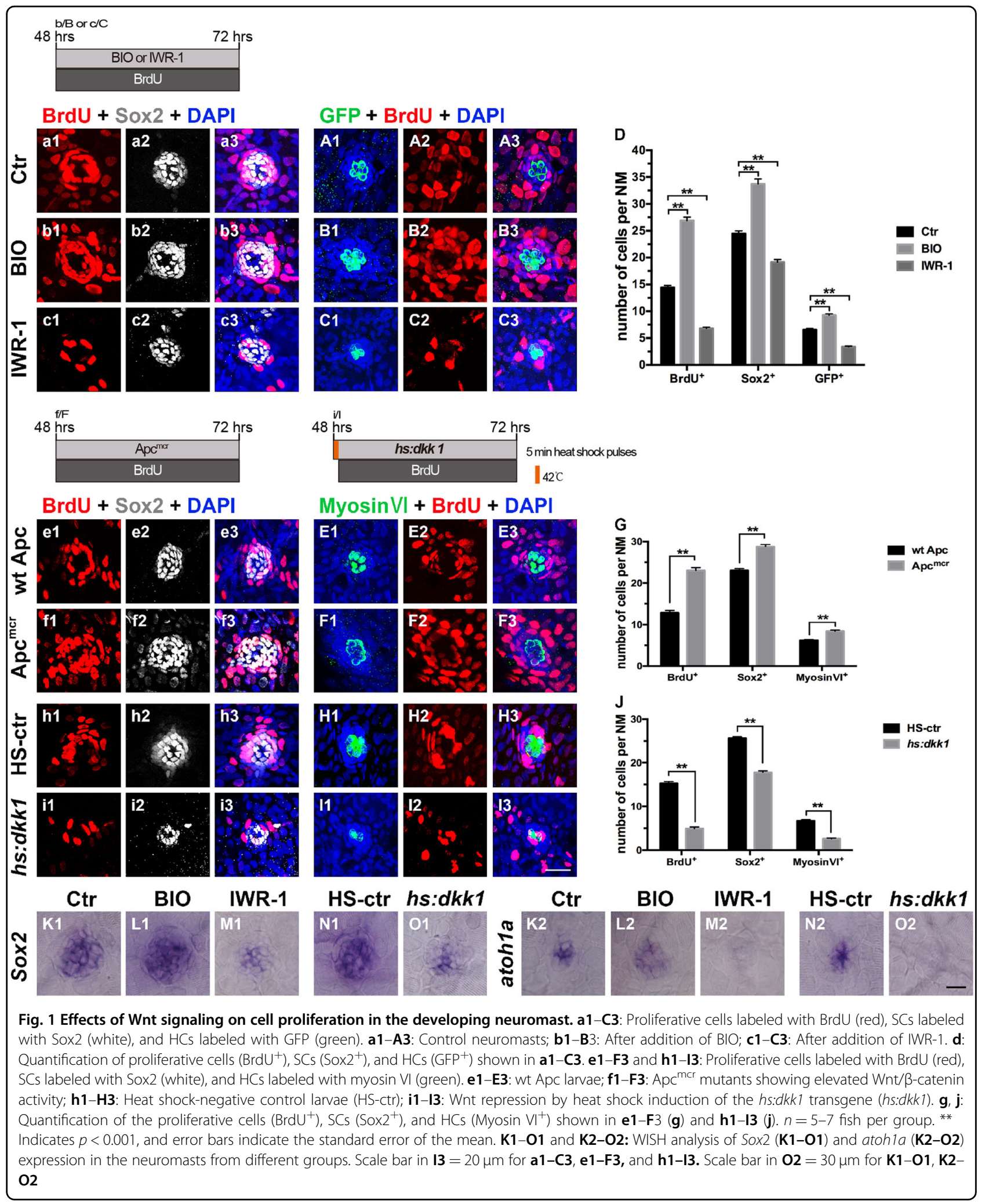

DMSO-treated control neuromasts (Fig. 1a1-a3, b1-b3, A1-A3, B1-B3). In contrast, IWR-1-treated embryos showed significantly fewer $\mathrm{BrdU}^{+}$cells, $\mathrm{HCs}$, and SCs in the developing neuromasts than did DMSO-treated controls (Fig. 1c1-c3, C1-C3, d), which is consistent with previous results ${ }^{19}$. Additionally, no significant change in 
apoptosis was observed after activation or suppression of Wnt activity (Supplementary Fig. 3).

To further verify the role of Wnt/ $\beta$-catenin signaling in neuromast development, we analyzed mutants and transgenic fish that respectively increase or decrease Wnt/ $\beta$-catenin signaling. The first was a recessive zebrafish mutation in the $a p c$ gene (referred to here as $\left.\mathrm{Apc}^{\mathrm{mcr}}\right)^{24,25}$, and the second was a heat-shock-inducible $d k k 1$ transgenic line (hsp70l:dkk1b-GFP, referred to here as hs: $d k k 1)^{26}$. In these experiments, myosin VI was used to label mature HCs. Consistent with the pharmacological results, the numbers of proliferating cells and differentiated cells (HCs and SCs) in neuromasts were significantly higher in $\mathrm{Apc}^{\mathrm{mcr}}$ larvae relative to those in wild-type (wt Apc) at 72 hpf (Fig. 1e1-e3, E1-E3, f1-f3, F1-F3, g), whereas heatshocked $d k k 1 b$-GFP larvae had significantly fewer proliferating cells and differentiated cells than nonheatshocked controls (HS-ctr) (Fig. 1h1-h3, H1-H3, i1-i3, I1-I3, j). WISH results showed that activating Wnt produced a significant increase in the mRNA level of the SC marker sox 2 and the HC marker atoh1a, whereas inhibition of Wnt signaling caused downregulation of both of genes compared with that observed in controls (Fig. $1 \mathrm{~K} 1-\mathrm{O} 1$ and $\mathrm{K} 2-\mathrm{O} 2)$.

\section{FGF signaling promotes cell proliferation and is required for HC differentiation}

FGF signaling is well known to be involved in multiple developmental processes, including normal otic placode formation and maintenance as well as pLL forma$\operatorname{tion}^{10,12,20,27,28}$. We, therefore, examined whether FGF signaling plays an important role in neuromast development in the zebrafish pLL. We first conducted a comprehensive expression analysis by means of WISH to examine the expression of known FGF signaling-related genes. In 72 hpf zebrafish larvae, expression of the FGF signaling receptor gene (fgfrl) and target gene (pea3) was clearly detectable within the neuromast (Supplementary Fig. 2A1-A2), indicating that this pathway is involved in early developmental processes in the neuromast. We studied the role of FGF signaling in neuromast development by blocking FGF with the small molecule SU5402, a specific FGF receptor tyrosine kinase inhibitor ${ }^{29}$. We treated $48 \mathrm{hpf}$ embryos with SU5402 at varying concentrations $(5,10$, or $15 \mu \mathrm{M})$ for $24 \mathrm{~h}$, with DMSO treatment as the control. At the highest dose $(15 \mu \mathrm{M})$, we observed evident larval death (10/12), whereas $5 \mu \mathrm{M}$ SU5402 did not cause developmental abnormalities or death. We then measured the expression of pea3 and fgfrl, and WISH showed that the expression of both genes was significantly downregulated after $5 \mu \mathrm{M}$ SU5402 treatment for $24 \mathrm{~h}$ compared to expression in DMSO controls (Supplementary Fig 2A1-A2 and B1-B2). Thus, we used $5 \mu \mathrm{M}$ SU5402 in subsequent experiments.
Quantification and comparison of $\mathrm{BrdU}^{+}$cells in the SU5402-treated larvae and DMSO-treated controls showed a significant reduction in the number of proliferating cells generated after Fgfr blockade (Fig. 2a1, a3, c1, c3, A2-A3, C2-C3, e), which was similar to inhibition of Wnt signaling. Loss of FGF signaling also resulted in a significant decrease in the development of neuromasts, as indicated by the robust loss of Sox $2^{+} \mathrm{SCs}$ and $\mathrm{GFP}^{+} \mathrm{HCs}$ (Fig. 2a2-a3, A1, A3, c2-c3, C1, C3, e).

\section{Wnt/ $\beta$-catenin signaling acts upstream of FGF signaling in neuromast development}

Because both Wnt/ $\beta$-catenin and FGF signaling components are expressed in the developing neuromast and are required for cell proliferation and $\mathrm{HC}$ differentiation, we analyzed the potential epistasis between Wnt and FGF signaling. First, we treated $48 \mathrm{hpf}$ embryos with $1 \mu \mathrm{M} \mathrm{BIO}$ alone for $6 \mathrm{~h}$ to activate $\mathrm{Wnt} / \beta$-catenin signaling. Then, we added $5 \mu \mathrm{M}$ SU5402 for $18 \mathrm{~h}$ along with BIO to inhibit FGF activity, which was compared to BIO treatment alone for $24 \mathrm{~h}$. Interestingly, the BIO-induced cell proliferation along with the increasing number of SCs and HCs was significantly disrupted by the FGFR1 antagonist SU5402 (Fig. 2b1- b3, B1-B3, d1-d3, D1-D3, e). We found no significant differences between the $\mathrm{BIO}+\mathrm{SU} 5402$ group and the SU5402 alone for $24 \mathrm{~h}$ group (Fig. 2c1-c3, C1-C3, d1-d3, D1-D3, e).

The same results were obtained when we used transgenic $\mathrm{Apc}^{\mathrm{mcr}}$ embryos instead of BIO to activate Wnt/ $\beta$-catenin signaling. At $54 \mathrm{hpf}, \mathrm{Apc}^{\mathrm{mcr}}$ embryos were incubated in $5 \mu \mathrm{M}$ SU5402 for $18 \mathrm{~h}$, and the wt Apc and wt SU5402 groups served as controls (Fig. 2f1-f3, F1-F3, h1-h3, H1-H3). When treated with SU5402, the increased numbers of $\mathrm{BrdU}^{+}$, Sox2 ${ }^{+}$, and Myosin $\mathrm{VI}^{+}$ cells in the neuromasts of $\mathrm{Apc}^{\mathrm{mcr}}$ larvae were all reduced (Fig. 2g1-g3, G1-G3, i1-i3, I1-I3, j). Similarly, there were no significant differences in the numbers of $\mathrm{BrdU}^{+}$, Sox $2^{+}$, or Myosin $\mathrm{VI}^{+}$cells between the $\mathrm{Apc}^{\mathrm{mcr}}+\mathrm{SU} 5402$ group and wt SU5402 group (Fig. 2h1-h3, H1-H3, i1-i3, I1-I3, j). Inhibiting FGF signaling caused downregulation of sox2 and atoh1a expression (Fig. 2M1 and M2) compared with control treatment (Fig. 2K1 and K2), whereas activation of Wnt followed by inhibition of FGF signaling led to a significant reduction in the mRNA level of both genes (Fig. 2N1 and N2) when compared with the level in the Wnt activation alone group (BIO) (Fig. 2L1 and L2).

Furthermore, we treated $48 \mathrm{hpf}$ wild-type embryos with SU5402 for $24 \mathrm{~h}$ to inhibit FGF signaling or treated them with SU5402 for $6 \mathrm{~h}$ first and then coincubated with BIO for another $18 \mathrm{~h}$. DMSO-treated larvae were used as controls. We found that the numbers of proliferating cells and differentiated cells were significantly reduced in SU5402-treated larvae compared with those in the controls and that BIO treatment had no effect on the reduced 







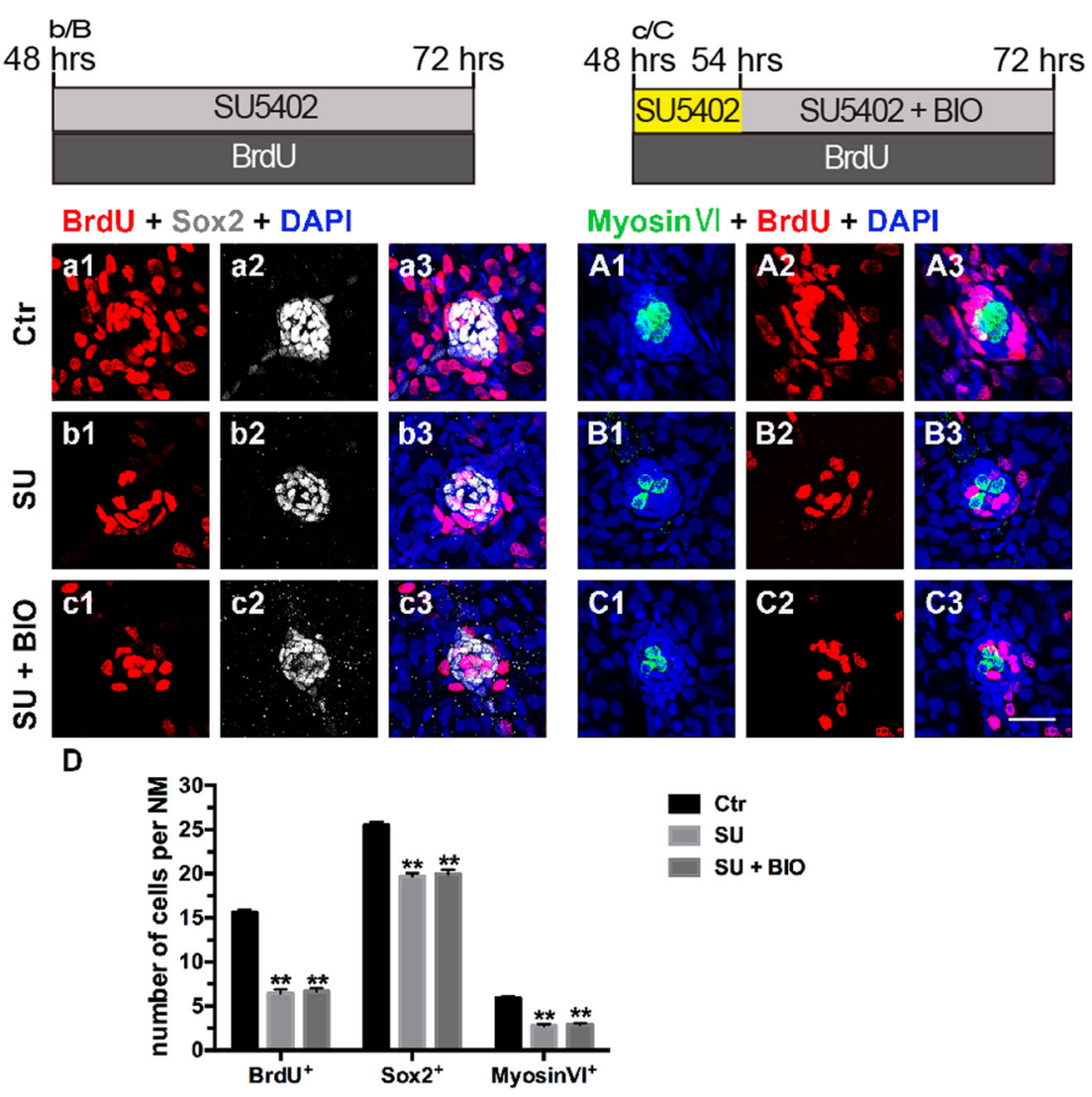

Fig. 3 Effects of Wnt activation on cell proliferation and differentiation in FGF-inhibited larvae. a1-C3: Proliferative cells labeled with BrdU (red), SCs labeled with Sox2 (white), and HCs labeled with myosin VI (green). a1-A3: Control neuromast; b1-B3: After addition of SU5402; c1-C3: After $6 \mathrm{~h}$ of incubation with SU5402, BIO and SU5402 were added for $18 \mathrm{~h}$; d: Quantification of the proliferative cells (BrdU ${ }^{+}$), SCs (Sox2 ${ }^{+}$), and HCs $\left(\right.$ Myosin $\mathrm{VI}^{+}$) shown in a1-C3. $n=5-7$ fish per group. ${ }^{* *}$ Indicates $p<0.001$, and error bars indicate the standard error of the mean. Scale bar in C3 $=$ $20 \mu \mathrm{m}$ for a1-C3

numbers of proliferating and differentiated cells in the neuromasts caused by SU5402 (Fig. 3).

\section{The reduced proliferation induced by $W n t / \beta$-catenin inhibition is partially rescued by upregulation of FGF} signaling

Given the expression of $f g f r 1$ in the neuromast and the critical role of FGF signaling during neuromast development in zebrafish, FGF activation might be responsible for cell proliferation. To test this possibility, we treated $48 \mathrm{hpf}$ zebrafish larvae with bFGF, also known as FGF-2, which is able to bind Fgfr1-3 and is involved in various biological processes, such as cell proliferation, angiogenesis, differentiation, and tumor development ${ }^{30-32}$. After treatment with bFGF $(20 \mathrm{ng} / \mathrm{ml})$ for $24 \mathrm{~h}$, the expression of pea 3 and $f g f r 1$ was robustly upregulated compared to the expression in unstimulated neuromasts, and no deformities were detected (Supplementary Figs 2A1-A2 and C1-C2). Furthermore, the addition of bFGF $(20 \mathrm{ng} / \mathrm{ml})$ increased cell proliferation and differentiation (Fig. 4a1-a3, A1-A3, c1-c3, C1-C3, e) and enhanced expression of atoh1a in neuromasts (Fig. 4K2 and M2).

To further confirm the relationship between Wnt and FGF signaling, we treated 48 hpf embryos with IWR-1 for $6 \mathrm{~h}$ and then incubated them in the presence or absence of bFGF for another $18 \mathrm{~h}$. Interestingly, significantly more $\mathrm{BrdU}^{+}$cells were observed in the neuromasts of the IWR$1+$ bFGF group than in those of the IWR-1 only group, indicating that bFGF treatment partly rescued the proliferative defect caused by IWR-1 inhibition (Fig. 4b1, b3, B2-B3, d1, d3, D2-D3, e). Furthermore, the IWR-1 + bFGF-treated group had significantly more Sox ${ }^{+}$SCs and $\mathrm{GFP}^{+} \mathrm{HCs}$ than the IWR-1-alone group (Fig. 4b2-b3, B1, B3, d2-d3, D1, D3, e) but fewer than the controls (Fig. 4a2-a3, A1, A3, e). Similar results were obtained when we heat shocked $d k k 1 b$-GFP transgenic embryos at $48 \mathrm{hpf}$ and then incubated them in $20 \mathrm{ng} / \mathrm{ml}$ bFGF (Fig. 4f1-f3, F1-F3, g1-g3, G1-G3, h1-h3, H1-H3, 


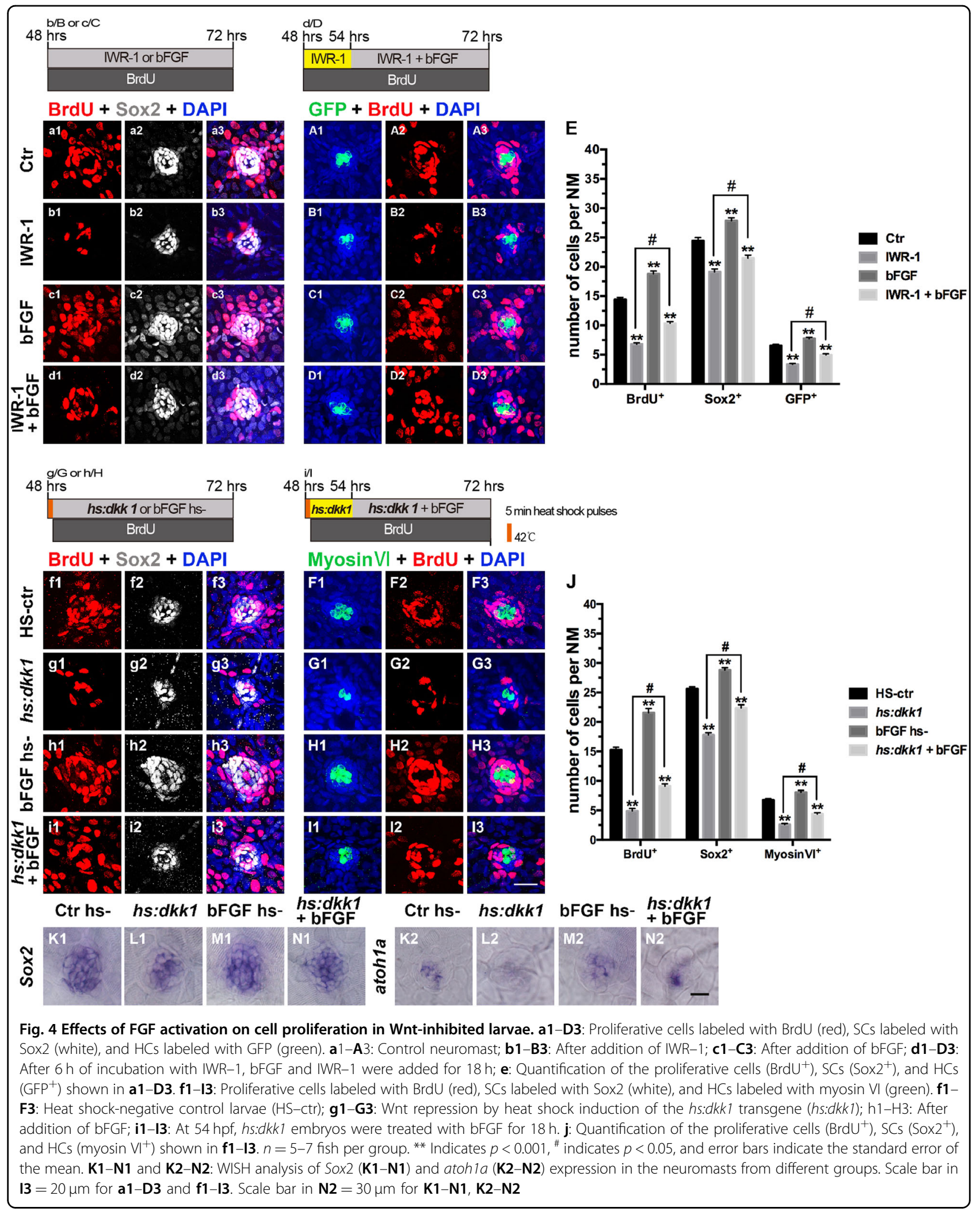






Fig. 5 Whole-mount in situ hybridization of $p 27, p 21$, and $c c$ nd 1 following regulation of Wnt and FGF signaling. A1-G3 In situ hybridization of p27 (A1-G1) p21 (A2-G2) and ccnd1 (A3-G3) following BIO (B1-B3), IWR-1 (C1-C3), SU5402 (D1-D3), bFGF (E1-E3), BIO+SU5402 (F1-F3), and IWR-1+bFGF (G1-G3) treatments. Scale bar in $\mathbf{G} 3=30 \mu \mathrm{m}$ for $\mathbf{A} \mathbf{1}-\mathbf{G} \mathbf{3}$

i1-i3, I1-I3, j). These experiments indicated that activating FGF signaling could partly rescue the proliferation failure caused by inhibiting Wnt/ $\beta$-catenin signaling, suggesting that FGF signaling acts downstream of Wnt/ $\beta$-catenin signaling. Although inhibiting Wnt signaling decreased the expression of sox2 and atoh1a (Fig. 4K1, L1, K2, and L2), bFGF treatment rescued the decreased expression of sox 2 and atoh1a induced by blocking Wnt signaling (Fig. 4L1-N1 and L2-N2).

\section{Wnt and FGF signaling are integrated to regulate proliferation during development}

Because one important role of both the Wnt and FGF signaling pathways during neuromast development is to promote cell proliferation, we focused on the cell cycle genes $p 27, p 21$, and $c c n d 1$ as possible downstream mediators of Wnt and FGF activity. Activation of FGF signaling didn't change the expression of $c c n d 1$ significantly but downregulated the expression of the cell cycle inhibitors $p 27$ and $p 21$ as shown in Fig. 5E1-E3, whereas blockage of FGF signaling using the FGFR inhibitor SU5402 resulted in a near complete loss of ccnd1 expression and an increase in $p 27$ and $p 21$ expression compared to control treatment (Fig. 5D1-D3 and A1-A3, respectively). When Wnt signaling was activated by $\mathrm{BIO}$, the expression of $p 27$ and $p 21$ was significantly downregulated in the neuromast (Fig. 5B1-B2); however, in the absence of FGF (BIO+SU5402), the expression of both genes was increased, especially the expression of $p 21$ (Fig. 5F1-F2). Meanwhile, overexpression of Wnt induced the expression of $c c n d 1$ (Fig. 5B3), and inhibition of FGF led to decreased ccnd1 levels (Fig. 5F3). In addition, inhibition of Wnt signaling by IWR-1 at $48 \mathrm{hpf}$ resulted in the near complete loss of ccnd 1 expression and an increase in $p 27$ and $p 21$ expression at $72 \mathrm{hpf}$ compared to control treatment (Fig. 5A1-A3 and $\mathrm{C} 1-\mathrm{C} 3$, respectively), while inhibition of Wnt followed by activation of FGF signaling led to a slight reduction in the mRNA levels of both the $p 27$ and $p 21$ genes when compared with IWR-1 treatment alone (Fig. 5C1-C2 and G1-G2). The activation of FGF signaling didn't rescue the reduction of $c c n d 1$ when inhibition of Wnt signaling (Fig. 5C3 and G3). Together, these results suggest that FGF signaling is essential for maintaining the expression of cell cycle genes.

We have shown that FGF signaling is required for cell proliferation in neuromasts and that FGF activity is regulated by $\mathrm{Wnt} / \beta$-catenin signaling. However, precisely which factors are involved in the interaction between the two pathways is unclear. To define the molecular network between Wnt and FGF during the proliferation of zebrafish neuromasts, we examined neuromasts for the expression of some target genes of the Wnt (ctnnb1, ctnnb2, and tcf7l2) and FGF (fgf3, fgf10, pea3, and $f g f r 1)$ signaling pathways. As expected, in BIO-treated larvae, the presumed Wnt target genes $c t n n b 1, c t n n b 2$, and $t c f 7 l 2$ were markedly upregulated in the neuromast, which was consistent with sustained activation of $\mathrm{Wnt} / \beta$-catenin signaling, whereas significant decreases were detected for these genes in the IWR-1 treatment group (Fig. 6A1-A3, $\mathrm{B} 1-\mathrm{B} 3$, and $\mathrm{C} 1-\mathrm{C} 3)$. Interestingly, Wnt activation significantly increased the expression levels of target genes associated with the FGF signaling pathway, such as $f g f 3$, fgf10, pea3, and fgfr 1 (Fig. 6A4-A7 and B4-B7), whereas the expression of these genes was strongly downregulated in IWR-1-treated larvae (Fig. 6C4-C7). These results further demonstrate that $\mathrm{Wnt} / \beta$-catenin signaling 


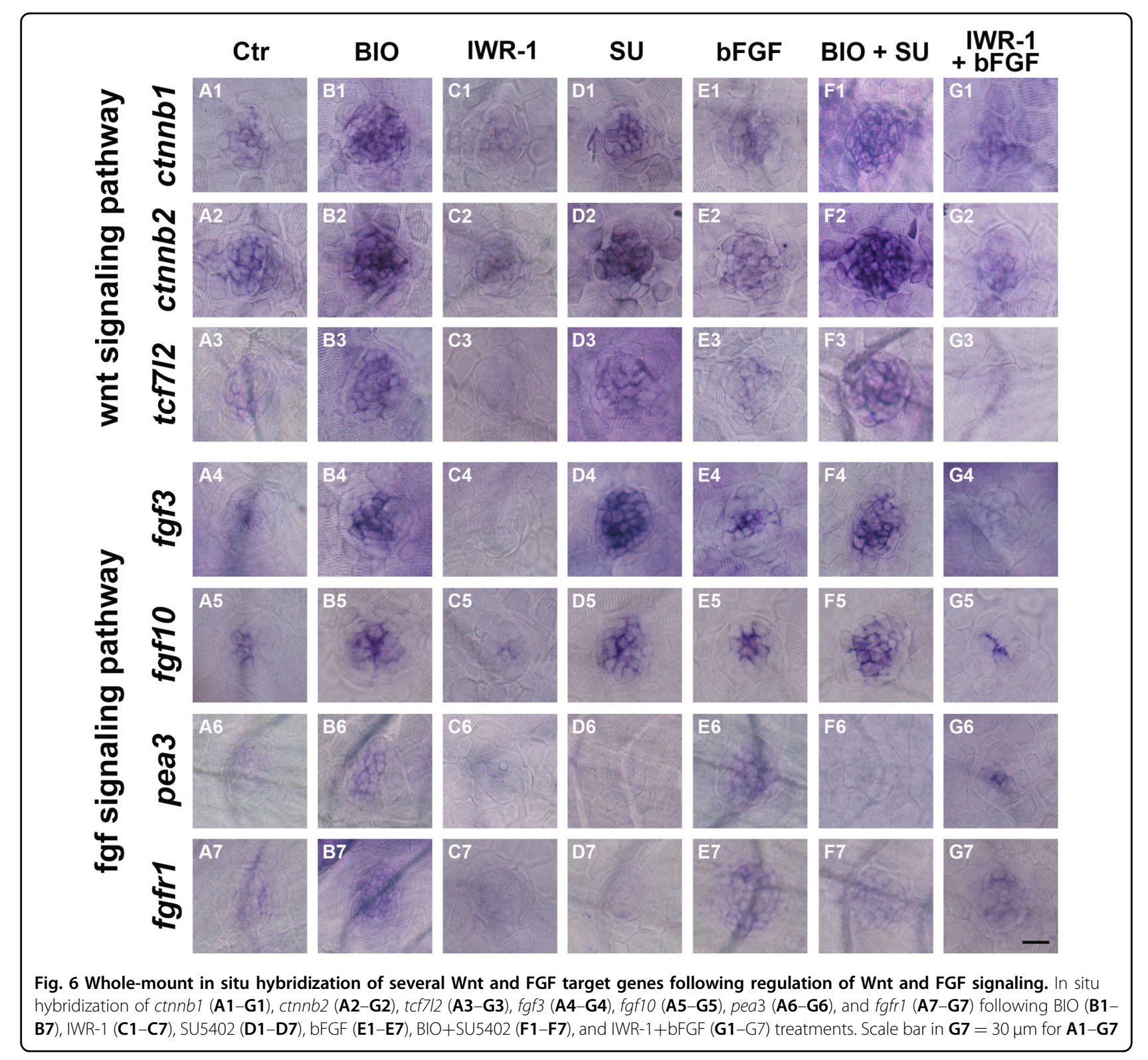

regulates FGF signaling during proliferation. To further determine how the Wnt and FGF signaling pathways interact, we stimulated FGF signaling with bFGF (Fig. 6E4-E7) and found that Wnt pathway gene expression was unaffected by bFGF treatment (Fig. 6E1-E3) compared to the expression in unstimulated neuromasts (Fig. 6A1-A3), suggesting that FGF signaling is regulated by Wnt signaling during the neuromast developmental stage. However, when SU5402 was used to inhibit FGF signaling, neuromast cells expressed much lower levels of pea3 and fgfr 1 (Fig. 6D6-D7) but expressed higher levels of ctnnb1, ctnnb2, tcf7l2, fgf3 and fgf10 (Fig. 6D1-D5) compared to controls (Fig. 6A1-A7), suggesting that fgfr 1 might restrict Wnt signaling in the developing neuromast.
To more clearly understand the relationship between Wnt and FGF, we analyzed the expression of Wnt and FGF target genes in the experimental sets with BIO, BIO + SU5402, IWR-1, and IWR-1 + bFGF. Expression of the FGF target genes pea 3 and $f g f r 1$ was significantly lower in $\mathrm{BIO}+$ SU5402 larvae than in larvae treated with BIO alone (Fig. 6F6-F7 and B6-B7, respectively), suggesting that FGF signaling is disrupted in the presence of the FGF inhibitor; however, the levels of $c t n n b 1, c t n n b 2$, and $t c f 7 l 2$ in the $\mathrm{BIO}+\mathrm{SU} 5402$-treated neuromasts were slightly higher than the levels in the BIO-treated larvae without FGF inhibition (Fig. 6F1-F3 and B1-B3). In the IWR-1+ bFGF group, there was increased expression of the FGF target genes (pea3 and fgfr1) (Fig. 6G6-G7 and C6-C7), 


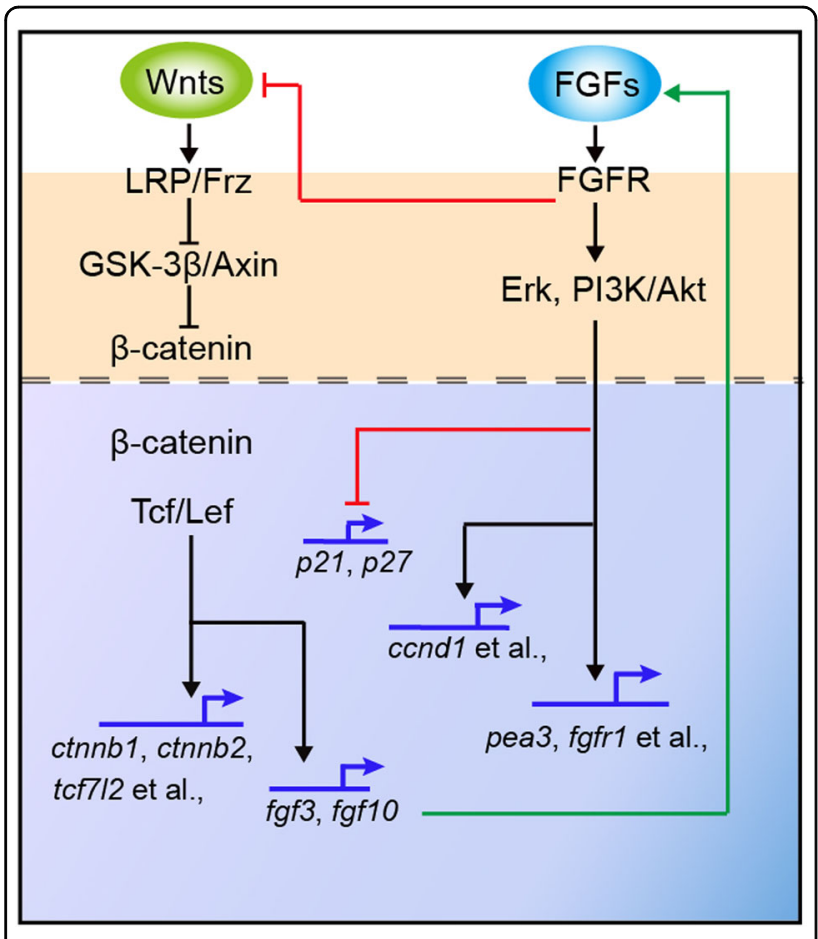

Fig. 7 A simple model of how the Wnt and FGF signaling pathways control cell proliferation in the zebrafish neuromast. Red lines show inhibition, and green lines indicate activation

whereas no changes were detected for Wnt target gene expression across the sensory domain compared with the expression in the IWR-1-alone group (Fig. 6G1-G3 and C1-C3). These results further confirmed that SU5402mediated fgfr1 inhibition might induce Wnt activation. Interestingly, the expression of $f g f 3$ and $f g f 10$ in BIO +SU5402 larvae was greatly increased, which could be caused by the presence of BIO (Fig. 6F4-F5 and B4-B5). In parallel, inhibition of Wnt signaling by IWR-1 treatment during neuromast development greatly reduced $f g f 3$ and $f g f 10$ expression (Fig. 6C4-C5), but bFGF treatment could not rescue their reduction in the neuromast (Fig. 6G4-G5). Taken together, these results indicate that $f g f 3$ and $f g f 10$ expression is dependent on Wnt activity during neuromast development (Fig. 7).

\section{Wnt and FGF signaling are integrated in $\mathrm{HC}$ regeneration after neomycin damage}

Wnt and FGF signaling control progenitor cell proliferation and $\mathrm{HC}$ differentiation. To further confirm the roles of both signaling pathways during $\mathrm{HC}$ regeneration, we killed the hair cells by incubating $5 \mathrm{dpf} \operatorname{tg}(B r n 3 c$ : $m G F P$ ) larvae with $400 \mu \mathrm{M}$ neomycin for $1 \mathrm{~h}$, followed by incubation in 6-well plates with or without the presence of different agents for a period of $24 \mathrm{~h}$ or $48 \mathrm{~h}(24 \mathrm{hpa}$ and $48 \mathrm{hpa})$. We then performed a BrdU $(10 \mathrm{mM})$ incorporation assay and quantified the number of regenerated HCs.
The BIO-treated larvae showed significantly more BrdU incorporation in the neuromasts than did DMSO-treated controls at both 24 and 48 hpa (Fig. 8a2-a3, A2-A3, b2-b3, B2-B3, i; Fig. 9a2-a3, A2-A3, b2-b3, B2-B3). Accordingly, the BIO-treated larvae had more HCs and SCs per neuromast at both 24 hpa and 48 hpa (Fig. 8a1, A1, b1, B1, h; Fig 9a1, A1, b1, B1, h). After BIO treatment, the numbers of $\mathrm{Sox}^{+} / \mathrm{BrdU}^{+}$and $\mathrm{GFP}^{+} / \mathrm{BrdU}^{+}$cells were both significantly greater than in the controls (Fig. $8 \mathrm{j}$ and Fig. 9i). In contrast, IWR-1-treated larvae had significantly fewer proliferating cells, $\mathrm{HCs}$, and SCs in the regenerating neuromast than did controls (Fig. 8c1-c3, $\mathrm{C} 1-\mathrm{C} 3, \mathrm{~h}, \mathrm{i}$; Fig. 9c1-c3, C1-C3, h). The numbers of $\mathrm{Sox}^{+} / \mathrm{BrdU}^{+}$and $\mathrm{GFP}^{+} / \mathrm{BrdU}^{+}$cells were also significantly lower after administration of IWR-1 (Fig. $8 j$ and Fig. 9i). All of these results are consistent with previous findings, suggesting that Wnt signaling induces regeneration in pLL neuromasts.

Loss of FGF signaling also resulted in a significant decrease in $\mathrm{HC}$ regeneration, as indicated by the significant loss of $\mathrm{BrdU}^{+}$regenerative cells, Sox $2^{+} \mathrm{SCs}$, and $\mathrm{GFP}^{+} \mathrm{HCs}$ at both $24 \mathrm{hpa}$ and $48 \mathrm{hpa}$ (Fig. 8d1-d3, D1-D3, h, i; Fig. 9d1-d3, D1-D3, h). To further study the role of the FGF signaling pathway during $\mathrm{HC}$ regeneration, we added bFGF to the fish water and found a significant increase in the numbers of proliferative cells, $\mathrm{HCs}$, and SCs compared with those in DMSO-treated control neuromasts (Fig. 8e1-e3, E1-E3, h, i; Fig. 9e1-e3, E1-E3, h). The number of cells double-labeled for Sox2 and BrdU or GFP and BrdU also significantly increased after the addition of bFGF (Fig. $8 j$ and Fig. 9i). These results indicate that FGF signaling has a significant effect on regeneration and $\mathrm{HC}$ production after neomycin exposure.

To determine if the increase in proliferation after Wnt activation during regeneration requires FGF signaling, we simultaneously activated Wnt signaling and inhibited FGF signaling using BIO and SU5402, respectively. Indeed, the BIO-induced increase in total proliferation was reduced to below normal levels after the simultaneous addition of SU5402, indicating that the majority of extra $\mathrm{BrdU}^{+}$cells formed after $\mathrm{BIO}$ treatment were likely due to an increase in FGF signaling (Fig. 8f2-f3, F2-F3, i; Fig. 9f2-f3 and F2F3). Because simultaneously activating Wnt and inhibiting FGF resulted in fewer proliferative cells compared to activating Wnt alone, we tested whether $\mathrm{HC}$ production was also affected by measuring the number of $\mathrm{GFP}^{+} \mathrm{HC}$ cells in the larval neuromasts. We found significant differences in the numbers of $\mathrm{GFP}^{+} \mathrm{HCs}$ and $\mathrm{GFP}^{+} / \mathrm{BrdU}^{+}$ double-positive cells between $\mathrm{BIO}+\mathrm{SU} 5402$ and BIOalone larvae (Fig. 9f1, F1, h, i). A reduction in the total number of SCs and Sox $2^{+} / \mathrm{BrdU}^{+}$cells in $\mathrm{BIO}+\mathrm{SU} 5402-$ treated larvae was also evident at $24 \mathrm{hpa}$ and $48 \mathrm{hpa}$ compared with that in the BIO-alone group (Fig. 8F1, F1, 


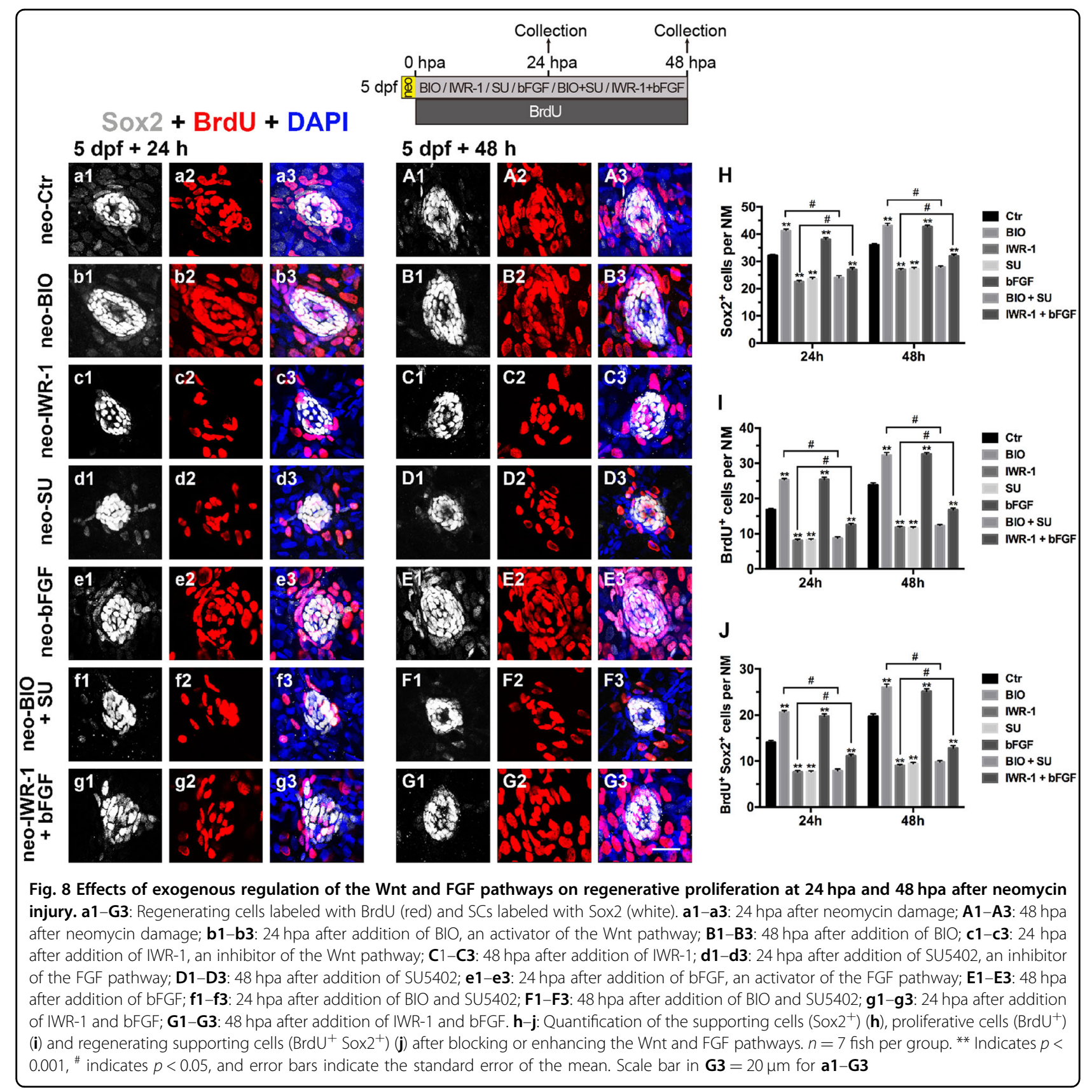

$h, j)$. This conclusion is supported by bFGF-induced FGF activation in Wnt-deficient larvae. Ablation of Wnt signaling with IWR-1 caused a reduction in proliferation that could be partly rescued by simultaneous activation of FGF with bFGF at 48 hpa (Fig. 8g2, G2, i; Fig. 9g2, G2), but there were still fewer $\mathrm{BrdU}^{+}$cells per neuromast than in the neomycin-alone controls (Fig. 8i; ${ }^{* * *} p<0.001$ ). Loss of HCs and SCs following inhibition of Wnt signaling was also partly restored by ectopic FGF activation (Fig. 8g1-g3, G1-G3, h; Fig. 9g1-g3, G1-G3, h).

\section{Discussion}

In the present study, we used a zebrafish model to gain new insights into the mechanism underlying the control of cell proliferation and fate determination in developing and regenerating neuromasts in the zebrafish PLL, and we provide evidence that activation of the Wnt and FGF pathways is crucial for promoting the proliferation and regeneration of $\mathrm{HCs}$ in the pLL. Our current study represents the first analysis indicating that Wnt acts through the FGF signaling pathway to promote progenitor 


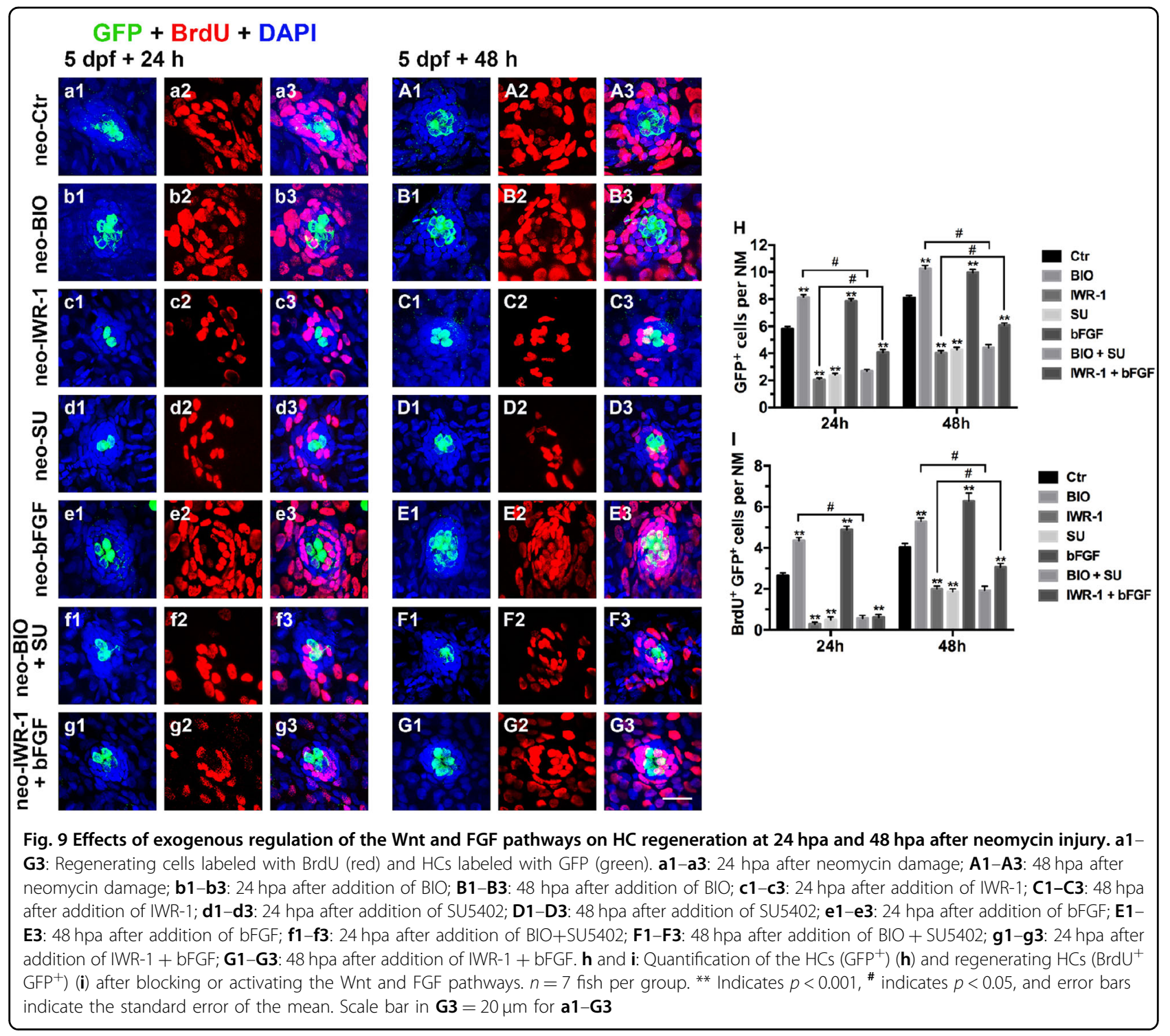

cell proliferation and regenerative cell proliferation in the zebrafish pLL neuromasts. These findings provide strong evidence that manipulation of the Wnt and FGF pathways will be useful for promoting $\mathrm{HC}$ regeneration in the mammalian inner ear.

Recent studies in zebrafish showed that activating Wnt signaling promotes the proliferation of neuromast progenitors and $\mathrm{HC}$ regeneration in both developing and damaged neuromasts; ${ }^{33,34}$ however, the exact mechanisms through which Wnt signaling stimulates cell proliferation and regeneration under these conditions remain unresolved. Here, we used $\mathrm{BIO}$ as a Wnt agonist to activate Wnt signaling in zebrafish neuromasts. Consistent with previous reports, our results indicate that activation of Wnt/ $\beta$-catenin signaling promotes cell proliferation in developing and regenerating neuromasts. More HCs and
SCs were observed in the neuromasts of the BIO-treated group, which suggests that both HCs and SCs were being overproduced and that most of the proliferated SCs differentiated into $\mathrm{HCs}$ after BIO treatment. Genetic activation of $\mathrm{Wnt} / \beta$-catenin signaling phenocopies the pharmacological activation by promoting progenitor cell proliferation and regenerative cell proliferation in neuromasts.

A number of studies have indicated the importance of FGF in inner ear development in many species ${ }^{35}$. Loss of FGF signaling in $f g f 3$ and $f g f 8$ double-deficient zebrafish not only causes failure of placode formation but also blocks HC development ${ }^{36}$, and Fgf3 and Fgf8 have been shown to act as upstream activators of the atoh1 gene, which is necessary for $\mathrm{HC}$ development during distinct inner ear developmental periods, including both the early 
development of the preotic placode and the later development of the otic vesicle ${ }^{37}$. Based on these studies, we hypothesized that early neuromast development requires the FGF signaling pathway. To test this hypothesis, we first performed in situ analyses and confirmed the expression of candidate ligands and receptors of the FGF signaling pathway in the neuromast, revealing that this pathway is potentially activated in the developing neuromast. Next, to test whether FGF signaling is involved in the proliferation of neuromast progenitors, we inhibited the FGF signaling pathway using SU5402. The results of our proliferation assay suggested that blockade of FGF signaling inhibited cell proliferation, similar to that observed when the Wnt signaling pathway was inactivated. Given that many similarities between developmental and regenerative processes in the pLL have been identified $^{2,5,38-40}$, we hypothesized that FGF activation would enhance regenerative proliferation and subsequent new $\mathrm{HC}$ generation in the pLL neuromast, similar to the effects of FGF activation during initial development. As hypothesized, neomycin-damaged larval zebrafish exposed to bFGF during recovery periods had significantly more SCs in their neuromasts than neomycin-alone control animals, indicating that increased cell proliferation had occurred, and this was followed by increased HC production. Together, these results suggest that FGF signaling plays a key role in regulating normal neuromast development and $\mathrm{HC}$ regeneration by promoting proliferation, similar to that observed for Wnt signaling in $\mathrm{HC}$ development and regeneration.

To identify the Wnt-FGF interactions that are required for cell proliferation in larval zebrafish neuromasts, we performed epistasis experiments using a combination of pharmacological and genetic approaches to manipulate Wnt and FGF activity. We compared cell proliferation with activated Wnt signaling alone or with activation of Wnt and inhibition of FGF signaling using the small molecule inhibitor SU5402. While activation of Wnt alone increased cell proliferation and induced greater $\mathrm{HC}$ numbers, it was unable to do so in the absence of FGF signaling. To further confirm that FGF functions downstream of Wnt signaling to promote cell proliferation in developing neuromasts, we used IWR-1 to downregulate the Wnt signal and then added bFGF to activate the FGF pathway. Our proliferation assay showed that bFGF treatment encouraged neuromast progenitors to proliferate and partly rescued the cell proliferation phenotype in the absence of Wnt signaling. In neomycin-damaged neuromasts, simultaneous manipulation of Wnt and FGF signaling activities showed that while Wnt signaling is sufficient to drive ectopic cell proliferation and subsequent $\mathrm{HC}$ regeneration, this pathway was able to do so only in the presence of functional FGF signaling.
In this work, we characterized the expression patterns of the FGF and Wnt pathway components in developing neuromasts in detail. We showed that Wnt activation significantly increased the expression of FGF components such as $f g f 3, f g f 10$, pea3, and $f g f r 1$, whereas their expression in IWR-1-induced Wnt-inhibited neuromasts was significantly reduced. Furthermore, stimulating FGF signaling through the addition of bFGF had no effect on the expression of Wnt components. In addition, no significant changes in the expression of $c t n n b 1$, ctnnb2, or $t c f 7 l 2$ were observed in the neuromasts of the IWR-1+bFGF group compared to that in the neuromasts of the IWR-1-alone group, indicating that there had been no reactivation of Wnt signaling by bFGF treatment after IWR-1 treatment. Taken together, our results suggest that the proproliferative effect induced by Wnt activation was mainly mediated by the FGF pathway, which is consistent with previous reports. For instance, Fgf8 levels are reduced in the absence of Wnt activity in mouse embryos $^{41}$, while FGF activity is enhanced in $\beta$-catenin overexpression embryos ${ }^{42,43}$, suggesting that FGF functions downstream of $\mathrm{Wnt} / \beta$-catenin signaling. Intriguingly, FGF activation did not change the expression of $f g f 3$ or $f g f 10$ in developing neuromasts, and thus, Wnt can be reasonably assumed to activate the FGF signaling pathway through $f g f 3$ and $f g f 10$. We also found that inhibiting FGF signaling with SU5402 resulted in downregulation of $f g f r 1$ and upregulation of $f g f 10$ and $f g f 3$ as well as several Wnt components, suggesting that a feedback mechanism involving Fgfr1 might operate during neuromast proliferation. A number of studies have shown that FGF components, such as $f g f 3$ and $f g f 10 a$, have mitogenic activity; ${ }^{44-46}$ however, their signaling functions in cell proliferation during neuromast development have not yet been explored. We showed that active Wnt and FGF signaling exerted their function by negatively regulating the cell cycle inhibitor genes $p 21$ and $p 27$ and positively regulating the $c c n d 1$ gene to permit cell proliferation. Sequential induction of Wnt signaling and inhibition of FGFR caused a complete loss of ccnd 1 expression and enhanced $p 21$ and $p 27$ expression in the neuromast, similar to SU5402 treatment alone, indicating an essential role of FGF signaling in maintaining the expression of cell cycle genes.

In this study, we showed that the Wnt and FGF pathways cooperate closely to regulate proliferation in the zebrafish neuromast. To fully understand the heterogeneity of the neuromast domain, it is necessary to identify all of the transcriptional targets that are activated or repressed by FGF and Wnt regulation during neuromast proliferation in zebrafish. Recently, many studies have shown that bFGF activates several intracellular pathways, including the RAS/ERK and PI3K/AKT cascades $^{47-49}$. Therefore, defining which signals act 
downstream of the Wnt-FGF interactions during proliferation in neuromasts is of great interest.

In summary, we have investigated the cross talk between the Wnt and FGF signaling pathways during cell proliferation and regeneration in the zebrafish neuromast and have shown that FGF activation enhances proliferation and promotes subsequent cell differentiation in the developing and regenerating neuromasts of the zebrafish pLL. Furthermore, we provide evidence that Wnt signaling activates FGF activity via $f g f 3$ and $f g f 10$ stimulation and that FGF signaling inhibits the Wnt pathway through the Wnt inhibitor fgfr 1 . Our findings contribute to studies on $\mathrm{HC}$ biology and provide a new avenue for understanding the signaling mechanisms that regulate cell proliferation during mammalian inner ear development.

\section{Acknowledgements}

We thank Xu Wang for providing the apc $c^{m a r}$ line and Tg(hsp70l:dkk1b-GFP) line and Yalin Huang for help with the confocal microscope. This work was supported by grants from the National Key R\&D Program of China (Nos. 2017YFA0103900, 2016YFC0905200) and the National Natural Science Foundation of China (Nos. 81620108005, 81800912, 81870728, 81470687, 81830029, 81230019).

\section{Author details}

${ }^{1}$ ENT institute and Otorhinolaryngology Department of Affiliated Eye and ENT Hospital, State Key Laboratory of Medical Neurobiology, Fudan University, Shanghai 200031, China. ${ }^{2}$ Institutes of Biomedical Sciences, Fudan University, Shanghai 200032, China. ${ }^{3} \mathrm{NHC}$ Key Laboratory of Hearing Medicine, Fudan University, Shanghai 200031, China. ${ }^{4}$ Shanghai Engineering Research Centre of Cochlear Implant, Shanghai 200031, China. ${ }^{5}$ The Institutes of Brain Science and the Collaborative Innovation Center for Brain Science, Fudan University, Shanghai 200032, China

\section{Conflict of interest}

The authors declare that they have no conflict of interest.

\section{Publisher's note}

Springer Nature remains neutral with regard to jurisdictional claims in published maps and institutional affiliations.

Supplementary information accompanies this paper at https://doi.org/ 10.1038/s12276-019-0247-x.

Received: 27 October 2018 Revised: 24 December 2018 Accepted: 31 December 2018.

Published online: 23 May 2019

\section{References}

1. Dambly-Chaudiere, C. et al. The lateral line of zebrafish: a model system for the analysis of morphogenesis and neural development in vertebrates. Biol. Cell. 95, 579-587 (2003).

2. Ghysen, A. \& Dambly-Chaudiere, C. Development of the zebrafish lateral line. Curr. Opin. Neurobiol. 14, 67-73 (2004).

3. Nicolson, T. The genetics of hearing and balance in zebrafish. Annu Rev. Genet. 39, 9-22 (2005)

4. Whitfield, T. T. Zebrafish as a model for hearing and deafness. J. Neurobiol. 53, 157-171 (2002).

5. Williams, J. A. \& Holder, N. Cell turnover in neuromasts of zebrafish larvae. Hear. Res. 143, 171-181 (2000).

6. Harris, J. A. et al. Neomycin-induced hair cell death and rapid regeneration in the lateral line of zebrafish (Danio rerio). J. Assoc. Res Otolanyngol. 4, 219-234 (2003).
7. Ma, E. Y., Rubel, E. W. \& Raible, D. W. Notch signaling regulates the extent of hair cell regeneration in the zebrafish lateral line. J. Neurosci. 28, 2261-2273 (2008).

8. Lopez-Schier, H. \& Hudspetht, A. J. A two-step mechanism underlies the planar polarization of regenerating sensory hair cells. Proc. Natl Acad. Sci. USA 103, 18615-18620 (2006).

9. Li, Q., Shirabe, K. \& Kuwada, J. Y. Chemokine signaling regulates sensory cell migration in zebrafish. Dev. Biol. 269, 123-136 (2004).

10. Aman, A. \& Piotrowski, T. Wnt/beta-catenin and Fgf signaling control collective cell migration by restricting chemokine receptor expression. Dev. Cell. 15, 749-761 (2008).

11. Aman, A. \& Piotrowski, T. Multiple signaling interactions coordinate collective cell migration of the posterior lateral line primordium. Cell Adh. Migr. 3, 365-368 (2009).

12. Nechiporuk, A. \& Raible, D. W. FGF-dependent mechanosensory organ patterning in zebrafish. Science 320, 1774-1777 (2008).

13. Lecaudey, V., Cakan-Akdogan, G., Norton, W. H. \& Gilmour, D. Dynamic Fgf signaling couples morphogenesis and migration in the zebrafish lateral line primordium. Development 135, 2695-2705 (2008).

14. Moon, R. T., Kohn, A. D., De Ferrari, G. V. \& Kaykas, A. WNT and beta-catenin signalling: diseases and therapies. Nat. Rev. Genet. 5, 691-701 (2004).

15. Gamba, L., Cubedo, N., Lutfalla, G., Ghysen, A. \& Dambly-Chaudiere, C. Lef1 controls patterning and proliferation in the posterior lateral line system of zebrafish. Dev. Dyn. 239, 3163-3171 (2010).

16. Aman, A., Nguyen, M. \& Piotrowski, T. Wnt/beta-catenin dependent cell proliferation underlies segmented lateral line morphogenesis. Dev. Biol. 349, 470-482 (2011).

17. Valdivia, L. E. et al. Lef1-dependent Wnt/beta-catenin signalling drives the proliferative engine that maintains tissue homeostasis during lateral line development. Development 138, 3931-3941 (2011).

18. Chitnis, A. B., Nogare, D. D. \& Matsuda, M. Building the posterior lateral line system in zebrafish. Dev. Neurobiol. 72, 234-255 (2012).

19. Jacques, B. E. et al. The role of Wnt/beta-catenin signaling in proliferation and regeneration of the developing basilar papilla and lateral line. Dev. Neurobiol. 74, 438-456 (2014).

20. Thisse, B. \& Thisse, C. Functions and regulations of fibroblast growth factor signaling during embryonic development. Dev. Biol. 287, 390-402 (2005).

21. Kimmel, C. B., Ballard, W. W., Kimmel, S. R., Ullmann, B. \& Schilling, T. F. Stages of embryonic development of the zebrafish. Dev. Dyn. 203, 253-310 (1995).

22. Thisse, C. \& Thisse, B. High-resolution in situ hybridization to whole-mount zebrafish embryos. Nat. Protoc. 3, 59-69 (2008).

23. Xiao, T., Roeser, T., Staub, W. \& Baier, H. A GFP-based genetic screen reveals mutations that disrupt the architecture of the zebrafish retinotectal projection. Development 132, 2955-2967 (2005).

24. Hurlstone, A. F. et al. The Wnt/beta-catenin pathway regulates cardiac valve formation. Nature 425, 633-637 (2003).

25. Peifer, M. \& Polakis, P. Wnt signaling in oncogenesis and embryogenesis-a look outside the nucleus. Science 287, 1606-1609 (2000).

26. Stoick-Cooper, C. L. et al. Distinct Wnt signaling pathways have opposing roles in appendage regeneration. Development 134, 479-489 (2007).

27. Maier, E. C. \& Whitfield, T. T. RA and FGF signalling are required in the zebrafish otic vesicle to pattern and maintain ventral otic identities. PLoS Genet. 10, e1004858 (2014).

28. Ono, K. et al. FGFR1-Frs2/3 signalling maintains sensory progenitors during inner ear hair cell formation. PLoS Genet. 10, e1004118 (2014).

29. Mohammadi, M. et al. Structures of the tyrosine kinase domain of fibroblast growth factor receptor in complex with inhibitors. Science 276, 955-960 (1997).

30. Okada-Ban, M., Thiery, J. P. \& Jouanneau, J. Fibroblast growth factor-2. Int J. Biochem. Cell Biol. 32, 263-267 (2000).

31. Korc, M. \& Friesel, R. E. The role of fibroblast growth factors in tumor growth. Curr. Cancer Drug Targets 9, 639-651 (2009).

32. Beenken, A. \& Mohammadi, M. The FGF family: biology, pathophysiology and therapy. Nat. Rev. Drug Disco. 8, 235-253 (2009).

33. Wada, $H$. et al. Wnt/Dkk negative feedback regulates sensory organ size in zebrafish. Curr. Biol. 23, 1559-1565 (2013).

34. Head, J. R., Gacioch, L., Pennisi, M. \& Meyers, J. R. Activation of canonical Wnt/catenin signaling stimulates proliferation in neuromasts in the zebrafish posterior lateral line. Dev. Dynam 242, 832-846 (2013).

35. Schimmang, T. Expression and functions of FGF ligands during early otic development. Int J. Dev. Biol. 51, 473-481 (2007). 
36. Leger, S. \& Brand, M. Fgf8 and Fgf3 are required for zebrafish ear placode induction, maintenance and inner ear patterning. Mech. Dev. 119, 91-108 (2002).

37. Millimaki, B. B., Sweet, E. M., Dhason, M. S. \& Riley, B. B. Zebrafish atoh1 genes: classic proneural activity in the inner ear and regulation by Fgf and Notch. Development 134, 295-305 (2007).

38. Hernandez, P. P., Olivari, F. A., Sarrazin, A. F., Sandoval, P. C. \& Allende, M. L. Regeneration in zebrafish lateral line neuromasts: expression of the neural progenitor cell marker sox2 and proliferation-dependent and-independent mechanisms of hair cell renewal. Dev. Neurobiol. 67, 637-654 (2007).

39. Millimaki, B. B., Sweet, E. M. \& Riley, B. B. Sox2 is required for maintenance and regeneration, but not initial development, of hair cells in the zebrafish inner ear. Dev. Biol. 338, 262-267 (2010).

40. Cotanche, D. A. \& Kaiser, C. L. Hair cell fate decisions in cochlear development and regeneration. Hear. Res. 266, 18-25 (2010).

41. Aulehla, A. et al. Wnt3a plays a major role in the segmentation clock controlling somitogenesis. Dev. Cell. 4, 395-406 (2003).

42. Aulehla, A. et al. A beta-catenin gradient links the clock and wavefront systems in mouse embryo segmentation. Nat. Cell Biol. 10, 186-193 (2008).
43. Dunty, W. C. Jr. et al. Wnt3a/beta-catenin signaling controls posterior body development by coordinating mesoderm formation and segmentation. Development 135, 85-94 (2008).

44. Konishi, M. et al. Role of Fgf10 in cell proliferation in white adipose tissue. Mol. Cell Endocrinol. 249, 71-77 (2006).

45. Shin, M., Noji, S., Neubuser, A. \& Yasugi, S. FGF10 is required for cell proliferation and gland formation in the stomach epithelium of the chicken embryo. Dev. Biol. 294, 11-23 (2006).

46. Itoh, N. \& Ornitz, D. M. Functional evolutionary history of the mouse Fgf gene family. Dev. Dynam 237, 18-27 (2008).

47. Ding, V. M. Y. et al. FGF-2 modulates Wnt signaling in undifferentiated hESC and iPS cells through activated PI3-KVGSK3 beta signaling. J. Cell Physiol. 225 417-428 (2010).

48. Israsena, N., Hu, M., Fu, W. M., Kan, L. X. \& Kessler, J. A. The presence of FGF2 signaling determines whether beta-catenin exerts effects on proliferation or neuronal differentiation of neural stem cells. Dev. Biol. 268, 220-231 (2004).

49. Katoh, M. \& Katoh, M. Cross-talk of WNT and FGF signaling pathways at GSK3 beta to regulate beta-catenin and SNAIL signaling cascades. Cancer Biol. Ther. 5. 1059-1064 (2006) 